\title{
Questes
}

Revue pluridisciplinaire d'études médiévales

$13 \mid 2008$

Figures royales à l'ombre du mythe

\section{Figures royales à l'ombre du mythe : éléments bibliographiques}

Julien Abed

\section{OpenEdition}

Édition électronique

URL : http://journals.openedition.org/questes/1473

DOI : 10.4000/questes. 1473

ISSN : 2109-9472

Éditeur

Les Amis de Questes

Édition imprimée

Date de publication : 15 janvier 2008

Pagination : 99-105

ISSN : 2102-7188

\section{Référence électronique}

Julien Abed, «Figures royales à l'ombre du mythe : éléments bibliographiques », Questes [En ligne], 13। 2008, mis en ligne le 01 janvier 2014, consulté le 15 septembre 2020. URL : http:// journals.openedition.org/questes/1473

\section{(c) Association des amis de «Questes »}




\section{Éléments bibliographiques}

\section{I. Études littéraires}

ANDRIEU, Éléonore, «Entre chair et esprit: petit exercice de déconstruction de l'héroïsme royal chez Suger ", Façonner son personnage au Moyen Âge. Actes du colloque d'Aix-en-Provence (9-11 mars 2006), éd. Chantal CONNOCHIE-BOURGNE, Aix-en-Provence, Publications de l'Université de Provence, 2007 (Senefiance, 53), p. 31-42.

«L'histoire des rois des Francs dans les Grandes Chroniques de France: des confirmations du mythe à l'aventure généalogique », Vérité poétique, Vérité politique. Mythes, modèles et idéologies politiques au Moyen Âge, éd. JeanChristophe CASSARD, Élisabeth GAUCHER et Jean KERHERVÉ, Brest, Université de Bretagne Occidentale, 2007, p. 23-46.

BATANY, Jean, «Propagande carolingienne et mythe carolingien: le programme de Louis le Pieux chez Ermold le Noir et dans le Couronnement de Louis », La Chanson de geste et le mythe carolingien. Mélanges René Louis, Saint-Père-sous-Vezelay, Musée archéologique régional, 1982, t. I, p. 313-340.

BAUMGARTNER, Emmanuèle, "L'image royale dans le roman antique: le Roman d'Alexandre et le Roman de Troie », De l'Histoire de Troie au livre du Graal, Orléans, Paradigme, 1994, p. 231-250 (paru d'abord dans Cours princières et châteaux. Pouvoir et culture du IX au XIII siècle en France du Nord, en Angleterre et en Allemagne, Actes du colloque de Soissons, 28-30 septembre 1987, éd. Danielle BUSCHINGER, Greifswald, Reineke-Verl., 1993, p. 25-44).

«La formation du mythe d'Alexandre au XII siècle: le Roman d'Alexandre et l'exotisme », Conter de Troie et d'Alexandre, éd. Laurence HARFLANCNER, Laurence MATHEY-MAILlE et Michelle SZKILNIK, Paris, Presses Sorbonne Nouvelle, 2006, p. 137-158 (traduction de « La fortuna di Alessandro nei testi francesi medievali del secolo XII e l'esotismo nel Roma d'Alexandre», Le Roman d'Alexandre. Riproduzione del ms. Venezia, Biblioteca Museo Correr, Correr 1493, Udine, R. Vattori, 1998, p. 11-28).

BEER, Jeanette M.A., A Medieval Caesar, Genève, Droz, 1976.

BENDER, Karl Heinz, «La genèse de l'image littéraire de Charlemagne, élu de Dieu, au XI ${ }^{\mathrm{e}}$ siècle », Boletín de la Real Academia de Buenas Letras de Barcelona, XXXI (1965-1966), p. 35-49. 
BouteT, Dominique, Charlemagne et Arthur, ou le roi imaginaire, Paris-Genève, Champion-Slatkine, 1992.

«Bâtardise et sexualité dans l'image littéraire de la royauté (XII ${ }^{\mathrm{e}}$ XIII siècles) », Femmes, mariages, lignages. Mélanges offerts à Georges Duby, Bruxelles, De Boeck Université, 1992, p. 55-68.

- $\quad$ "Royauté et transcendance dans la fiction littéraire au temps de Philippe Auguste ", Personne, personnage et transcendance aux XII et XIII siècles, éd. MarieÉtiennette BÉLY et Jean-René VALETTE, Lyon, Presses Universitaires de Lyon, 1999, p. 35-59.

«De Pandragon et d'Uter à Uterpandragon: mythe, idéologie et construction littéraire dans le Merlin de Robert de Boron ", Merlin, roman du XIII siècle de Robert de Boron, dir. Danielle QuÉRUEL et Christine FERLAMPIN-ACHER, Paris, Ellipses, 2000, p. 29-40.

«Entre le réel et l'imaginaire : les rivalités successorales et l'idéologie de la légitimité dans la littérature française du XII siècle ", Royautés imaginaires (XII ${ }^{e}$ $X V I^{e}$ siècle), éd. Anne-Hélène ALLIROT, Gilles LECUPPRE et Lydwine SCORDIA, Turnhout-Poitiers, Brepols-CESCM, 2005, p. 5-18.

Charlemagne et l'épopée romane. Actes du VII Congrès International de la Société Rencesvals, Paris, Les Belles Lettres, 1978.

CizeK, Alexander, «La Rencontre de deux sages: Salomon le 'pacifique' et Alexandre le Grand dans la légende hellénistique et médiévale », Images et signes de l'Orient dans l'Occident médiéval, Marseille, Publications de l'Université de Provence, 1982, p. 77-99 (coll. Senefiance, 11).

«Alexandre le Grand et 'li douze pers de Gresce' dans le Roman français d'Alexandre ", La Réception de l'Antiquité au Moyen Âge, Vienne, Wiener Arbeiten zur Germanischen Altertumskunde, 1982, p. 169-201.

Cockshaw, Pierre (dir.), VAn Den Bergen-Pantens, Christiane (éd.), L'Ordre de la Toison d'or, de Philippe le Bon à Philippe le Beau (1430-1505) : idéal ou reflet d'une société ?, Bruxelles, Bibliothèque royale de Belgique / Turnhout, Brepols, 1996.

Croisy-Naquet, Catherine, Écrire l'histoire romaine au début du XIII siècle: l'Histoire ancienne jusqu'à César et les Faits des Romains, Paris, Champion, 1999.

DOUDET, Estelle, « Le miroir de Jason : la Grèce ambiguë des écrivains bourguignons au $\mathrm{XV}^{\mathrm{e}}$ siècle », La Grèce antique sous le regard du Moyen Âge occidental. Actes du $X V^{e}$ colloque international de l'Académie des Inscriptions et Belles Lettres, Nice, octobre 2004, Cahiers de la Villa Kérylos 16, 2005, p. 175-193.

DOUTREPONT, Georges, La Littérature française à la cour des ducs de Bourgogne, Paris, Champion, 1909. 
FLUTRE, Louis-Ferdinand, Li Fait des Romains dans les littératures française et italienne du XIII au XV siècle, 1932, Genève, Slatkine Reprints, 1974.

Gaullier-Bougassas, Catherine, "Alexandre et Candace dans le Roman d'Alexandre de Paris et le Roman de toute chevalerie de Thomas de Kent », Romania, 112 (1991), p. 18-44.

«Le mythe d'Alexandre le Grand dans l'Histoire ancienne jusqu'à César ", Vérité poétique, Vérité politique. Mythes, modèles et idéologies politiques au Moyen Âge, éd. Jean-Christophe CASSARD, Élisabeth GAUCHER et Jean KERHERVÉ, Brest, Université de Bretagne Occidentale, 2007, p. 193-207.

Gosman, Martin, «Les derniers jours d'Alexandre dans le Roman d'Alexandre : fin d'une vie exemplaire », dans Alexander the Great in the Middle Ages. Ten Studies on the Last Days of Alexander in Literary and Historical Writing, éds. W. J. AERTS, Jos. M. M. HERmANS, and Elizabeth VISSER, Nimègue, Alfa, 1978, p. 170-201.

- $\quad$ «Le Roman de toute chevalerie et le public visé. La légende au service de la royauté », Neophilologus, 72 (1988), p. 335-343.

GRISWARD, Joël H., «Le motif de l'épée jetée au lac : la mort d'Arthur et la mort de Batradz », Romania, 90 (1969), p. 289-340 et 473-514.

- Archéologie de l'épopée médiévale: structures trifonctionnelles et mythes indo-européens dans le cycle des Narbonnais, avec une préface de Georges DuMÉZIL, Paris, Payot, 1981.

«Uter Pendragon, Arthur et l'idéologie royale des Indo-européens. Structure trifonctionnelle et roman arthurien », Le Moyen Âge maintenant. Revue Europe, 654 (octobre 1983), p. 111-120.

- $\quad$ "Lear, le péché du roi et le partage du monde », Cahiers de civilisation médiévale, 45 (2002), p. 25-37.

GRUBEN, Françoise de, Les Chapitres de la Toison d'or à l'époque bourguignonne (1430-1477), Louvain, Leuven University Press, 1997.

HAUGEARD, Philippe, «L'enchantement du don. Une approche anthropologique de la largesse royale dans la littérature médiévale (XII-XIII siècles) », Cahiers de Civilisation Médiévale, 195 (Juillet-Septembre 2006), p. 295-312.

«Richesse ostentatoire et domination politique: l'actualisation médiévale d'un substrat mythique dans deux chansons de geste (Aymeri de Narbonne et Le Pèlerinage de Charlemagne) ", dans Vérité poétique, Vérité politique. Mythes, modèles et idéologies politiques au Moyen Âge, éd. Jean-Christophe CASSARD, Élisabeth GAUCHER et Jean KERHERVÉ, Brest, Université de Bretagne Occidentale, 2007, p. 225-239.

HolzermaYR, Katharina, «Le mythe d'Arthur, la royauté et l'idéologie », Annales ESC, 1984, p. 480-494. 
KENNEDY, Elspeth M., "King Arthur in the first part of the prose Lancelot», Medieval miscellany presented to Eugène Vinaver by pupils, colleagues and friends, éd. Armel H. DiverRES, Franck Edmund SuTCLIFFE et Frederick WhITEHEAD, New York, Barnes \& Noble, Manchester University Press, 1965, p. 186-195.

KöHLER, Erich, L'Aventure chevaleresque. Idéal et réalité dans le roman courtois, Paris, Gallimard, 1974 ( $1^{\text {ère }}$ éd. en langue originale : 1956).

LEEKER, Joachim, Die Darstellung Cäsars in den romanischen Literaturen des Mittelalters, Francfort, V. Klostermann, 1986.

LeHManN, Paul, Das literarische Bild Karls des Grossen vornehmlich im lateinischen Schrifttum des Mittelalters, Münich, 1934.

MarignaC, Lucie, "Philippe le Bon et l'Ordre de la Toison d'or : les enjeux d'une référence mythique », Mythes et histoire, RAZO. Cahiers du Centre d'Études Médiévales de Nice, 12 (1992), p. 87-112.

Mathey-Maille, Laurence, « Le roi Leir chez Geoffroy de Monmouth et Wace : la naissance d'une figure mythique ", Pour une mythologie du Moyen Âge, éd. Dominique BoUTET et Laurence HARF-LANCNER, Paris, École Normale Supérieure, 1988, p. 99-115.

«Le roi Arthur chez Geoffroy de Monmouth et Wace : la naissance du héros », Arturus rex. Acta conventus Lovaniensis. 1987, éd. Willy VAN HoECKE, Gilbert TOURNOY et Werner VERBEKE, Leuven, Leuven University Press, 1991, p. 222-229.

«Entre vérité politique et vérité poétique : la figure d'Henri $\mathrm{I}^{\mathrm{er}}$ dans quelques chroniques anglo-normandes», dans Vérité poétique, Vérité politique. Mythes, modèles et idéologies politiques au Moyen Âge, éd. Jean-Christophe CASSARD, Élisabeth GAUCHER et Jean KERHERVÉ, Brest, Université de Bretagne Occidentale, 2007, p. 317-325.

MÉniel, Bruno, et Ribémont, Bernard (dir.), La Figure de Jules César au Moyen Âge et à la Renaissance, Cahiers de recherches médiévales, $\mathrm{n}^{\circ} 13$ et 14 (numéros spéciaux, 2006 et 2007).

Mimoso-RuIz, Duarte, Médée antique et moderne. Aspects rituels et socio-politiques d'un mythe, Paris, Ophrys, 1982.

PARIS, Gaston, Histoire poétique de Charlemagne, Paris, 1865, 2éd. 1905.

Perez-Simon, Maud, "Mise en scène du corps et discours politique dans un manuscrit du Roman d'Alexandre en prose du XIV siècle », Conter de Troie et d'Alexandre, éd. Laurence HARF-LANCNER, Laurence MATHEY-MAILLE et Michelle SZKILNIK, Paris, Presses Sorbonne Nouvelle, 2006, p. 271-289. 
RAYNAUD, Christiane, «Les représentations du pouvoir royal du XIII ${ }^{\mathrm{e}}$ au XV $\mathrm{XV}^{\mathrm{e}}$ siècle : le cas d'Alexandre ", Images de l'Antiquité dans la littérature française, le texte et son illustration, éd. Emmanuèle BAUMGARTNER et Laurence HARF-LANCNER, Paris, Presses de l'École Normale Supérieure, 1993, p. 59-71.

ViNCENSINI, Jean-Jacques, « Impatience et impotence. L'étrangeté des rois du château du Graal dans le Conte du Graal », Romania, 116 (1998), p. 112-130.

WALTER, Philippe, Arthur, l'ours et le roi, Paris, Imago, 2002.

\section{Travaux d'histoire et d'anthropologie historique}

Albert, Jean-Pierre, Odeurs de sainteté. La mythologie chrétienne des aromates, Paris, Éditions de l'EHESS, 1990, Troisième partie : « Histoire des rois », p. 249-336.

- «Le roi et les merveilles. À propos de la légende du Prêtre Jean », Cahiers de littérature orale. Rêver le roi, 29 (1991), p. 17-45.

Alibert, Dominique, Les Carolingiens et leurs images. Iconographie et idéologie, thèse de doctorat dir. par Olivier GUILLOT, soutenue à l'Université de Paris IVSorbonne en 1994.

Allirot, Anne-Hélène, Lecuppre, Gilles et Scordia, Lydwine (éd.), Royautés imaginaires (XII -XVI siècle), Turnhout-Poitiers, Brepols-CESCM, 2005.

Anton, Hans Hubert, Fürstenspiegel und Herrscherethos in der Karolingerzeit, Bonn, L. Röhrscheid, 1968.

Bertelli, Sergio, Il corpo del re. Sacralità del potere nell'Europa medievale e moderna, Florence, Ponte Alle Grazie, 1990.

BLANCHARD, Joël (éd.), Représentation, pouvoir et royauté à la fin du Moyen Âge, postface de Philippe CONTAMINE, Paris, Picard, 1995.

BLANCHARD, Joël et MüHLETHALER, Jean-Claude (éd.), Écriture et pouvoir à l'aube des temps modernes, Paris, Presses Universitaires de France, 2002.

BLOCH, Marc, Les Rois thaumaturges. Étude sur le caractère surnaturel attribué à la puissance royale, particulièrement en France et en Angleterre, Strasbourg, Publications de la Faculté des Lettres de 1'Université de Strasbourg, 1924 ; rééd. avec une préface de Jacques LE GOFF, Paris, Gallimard, 1983.

Boureau, Alain, et INGERflom, Claudio Sergio (éd.), La Royauté sacrée dans le monde chrétien (colloque de Royaumont, mars 1989), Paris, Éditions de l'EHESS, 1992. 
Chennaf, Sarah, et REDon, Odile, «Les miracles de Saint Louis », Les Miracles, miroirs des corps, éd. Jacques GELIS et Odile REDON, Saint-Denis, Presses Universitaires de Vincennes, 1983, p. 53-85.

Folz, Robert, Les Saints Rois du Moyen Âge en Occident (VI ${ }^{e}-X I I I^{e}$ siècles), Bruxelles, Société des Bollandistes, 1984.

GAbORIT-Chopin, Danielle, Regalia. Les instruments du sacre des rois de France. Les "Honneurs de Charlemagne », Paris, Éditions de la Réunion des musées nationaux, 1987.

GRABOÏs, Aryeh, «L'idéal de la royauté biblique dans la pensée de Thomas Becket », Thomas Becket : actes du colloque international de Sédières, 19-24 août 1973, Paris, Beauchesne, 1975, p. 103-110.

Hirel, Sophie, «Le roi, le moine et la cloche. Genèse d'un modèle et tentative de mythification du roi Ramire II d'Aragon (1135-1137», Vérité poétique, Vérité politique. Mythes, modèles et idéologies politiques au Moyen Âge, éd. Jean-Christophe CASSARD, Élisabeth GAUCHER et Jean KERHERVÉ, Brest, Université de Bretagne Occidentale, 2007, p. 241-260.

KANTOROWICZ, Ernst, Euvres, Paris, Gallimard, 2000 (contient L'Empereur Frédéric II, première éd. : Stuttgart, 1927 ; trad. française : 1987, et Les Deux Corps du roi. Essai sur la théologie politique au Moyen Âge, $1^{\text {ère }}$ éd. : Princeton, 1957 ; trad. française : 1989).

KRYNEN, Jacques, L'Empire du roi. Idées et croyances politiques en France (XIII ${ }^{e}$ $X V^{e}$ siècle), Paris, Gallimard, 1993.

LACHAUd, Frédérique, et SCORDIA, Lydwine, Le Prince au miroir de la littérature politique de l'Antiquité aux Lumières, Publications des Universités de Rouen et du Havre, 2007.

LECUPPRE, Gilles, L'Imposture politique au Moyen Âge: la seconde vie des rois, Paris, Presses Universitaires de France, 2005.

LE GOFF, Jacques, « Royauté biblique et idéal monarchique médiéval : Saint Louis et Josias », Les Juifs au regard de l'histoire. Mélanges Bernhard Blumenkranz, éd. Gilbert DAHAN, Paris, Picard, 1985, p. 157-168.

- "Le mal royal au Moyen Âge : du roi malade au roi guérisseur », Mediaevistik, 1 (1988), p. 101-109.

« La genèse du miracle royal », Marc Bloch aujourd'hui. Histoire comparée et sciences sociales, Paris, Éditions de l'EHESS, 1990, p. 147-156.

troisième parties).

Saint Louis, Paris, Gallimard, 1996 (notamment la deuxième et la 
- «Roi », Dictionnaire raisonné de l'Occident médiéval, Paris, Fayard, 1999, p. 985-1004.

Pastoureau, Michel, L'Ours : histoire d'un roi déchu, Paris, Le Seuil, 2007.

REYDELLET, Marc, La Royauté dans la littérature latine, de Sidoine Apollinaire à Isidore de Séville, Rome, École Française de Rome / Paris, diff. De Boccard, 1981.

RICHÉ, Pierre, «La Bible et la vie politique dans le haut Moyen Âge », Le Moyen Âge et la Bible, dir. Pierre RICHÉ et Guy LOBRICHON, Paris, Beauchesne, 1984, p. 385-400.

SASSIER, Yves, Royauté et idéologie au Moyen Âge. Bas-Empire, monde franc, France (IV ${ }^{e}$-XII $I^{e}$ siècle), Paris, Armand Colin, 2002.

SCHRAMM, Percy Ernt, Herrschaftszeichen und Staatsymbolik. Beitrage zu Ihrer Geschichte vom dritten bis zum Sechzehnten Jahrhundert, Schriften der Monumenta Germaniae Historica, Stuttgart, Hiersemann Verlag, 1954-1956 (extraits traduits et présentés par Philippe BRAUNSTEIN dans Le Débat 14, 1981).

«Das Alte und das Neue Testament in der Staatslehre und der Staatssymbolik des Mittelalters », Settimane di studio del Centro italiano di studi sull'Alto Medioevo, Spolète, 10 (1963), p. 229-255.

STEGER, Hugo, "David rex et propheta». König David als vorbildliche Verkörperung des Herrschers und Dichters im Mittelalter, nach Bilddarstellungen des achten bis zwölften Jahrhunderts, Nürnberg, H. Carl, 1961. 